\title{
Eastern European and Asian-born populations are prone to gastric cancer: an epidemiologic analysis of foreign-born populations and gastric cancer
}

\author{
Shria Kumara, Alejandro Mantero ${ }^{b}$, Cindy Delgadoc, Barbara Dominguezc, Nadine Nuchovich', \\ David S. Goldbergc \\ Perelman School of Medicine at the University of Pennsylvania; University of Miami Miller School of Medicine, USA
}

\section{Abstract}

\begin{abstract}
Background The highest incidence of gastric cancer is in East Asia, corresponding to a high prevalence of Helicobacter pylori (H. pylori), yet other regions with a similarly high prevalence of $H$. pylori have lower cancer rates. Foreign-born persons who immigrate to the United States are thought to remain at high-risk for gastric cancer, but this has not been confirmed by large population-based studies.
\end{abstract}

Methods We evaluated total and foreign-born populations in metropolitan statistical areas (MSAs). Cardia and non-cardia gastric adenocarcinomas diagnosed between 2006 and 2016 were identified using the Surveillance, Epidemiology, and End Results Program. Generalized linear regression models determined whether the incidence of gastric cancer in each MSA was associated with specific foreign-born populations.

Results Among 32 MSAs, we identified 55,937 patients with gastric adenocarcinoma. A greater percentage of Eastern European-born individuals in an MSA was associated with a higher incidence of cardia cancers (coefficient 1.32, $\mathrm{P}=0.02$ ). Evaluating Asian-born populations alone, a greater percentage of Japanese-born individuals was associated with a higher incidence of noncardia cancers (coefficient 2.48, $\mathrm{P}=0.03$ ), whereas Korean or Chinese origin was not associated with a significantly higher risk.

Conclusions On a population level, a greater percentage of Eastern European-born individuals is associated with a higher incidence of cardia gastric adenocarcinomas. Among Asian-born individuals, Korean or Chinese origin was not associated with a significantly higher risk, but a greater percent of persons born in other Asian countries, including Japan, was associated with a higher incidence of non-cardia gastric adenocarcinomas in an MSA.

Keywords Immigrants, gastric cancer, Helicobacter pylori

Ann Gastroenterol 2021; 34 (1): 1-9

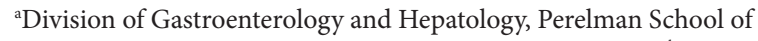
Medicine at the University of Pennsylvania (Shria Kumar); ${ }^{b}$ Division of Biostatistics, University of Miami Miller School of Medicine (Alejandro Mantero); 'Division of Digestive Health and Liver Diseases, Department of Medicine, University of Miami Miller School of Medicine (Cindy Delgado, Barbara Dominguez, Nadine Nuchovich, David S. Goldberg), USA

Conflict of Interest: Shria Kumar: Travel (Boston Scientific Corporation, Olympus Corporation); David S. Goldberg: Research grant support (Gilead, Merck, AbbVie, Zydus). The other authors have no conflict of interest to disclose.

Correspondence to: Shria Kumar / David S. Goldberg, 1120 NW 14th St, Room 807, Miami, FL 33136, USA,

e-mail: dsgoldberg@med.miami.edu

Received 12 November 2020; accepted 11 January 2021; published online 3 June 2021

DOI: https://doi.org/10.20524/aog.2021.0640

\section{Introduction}

Gastric cancer is the third most common cause of cancer deaths in the world [1]. It is recognized to have 2 distinct subtypes: cardia and non-cardia [1-3]. Cardia cancers are considered to be extensions or variants of esophageal adenocarcinoma and are more prevalent in non-Hispanic whites [4-6]. Non-cardia cancers, which remain the more common anatomic subtype of gastric cancer, are more prevalent in racial and ethnic minorities and are strongly linked to Helicobacter pylori (H. pylori), a class I carcinogen that, given the right host and environment, can trigger mucosal changes that result in a precancerous cascade $[7,8]$.

H. pylori is a bacterium thought to be acquired in childhood, particularly in areas that are impoverished or have poor sanitary conditions [9]. It is considered responsible for the 
greater incidence of gastric adenocarcinoma in the Middle East, East and Southeast Asia, the Mediterranean, Eastern Europe, and Central and South America [9]. Persons who immigrate to the Unites States (US) from these regions may continue to carry an increased future risk of gastric cancer, attributable to the bacterium $[8,10-12]$. However, simply originating from a region with a high prevalence of $H$. pylori does not necessarily translate to gastric cancer. This is best illustrated by the "African enigma", which refers to the discordant association between a high prevalence of $H$. pylori and a low prevalence of gastric cancer in Africa, and is supported by the disparate rates of gastric cancer throughout Middle Eastern countries, despite a uniformly high burden of $H$. pylori $[13,14]$.

In the US, studies continue to attempt to identify the group most likely to benefit from gastric cancer screening in the US, and immigrants are considered a potential high-risk group $[2,8,15]$. Foreign-born populations who emigrated from countries with a high-incidence of gastric cancer are thought to have a higher incidence of gastric cancer than do their US-born peers, due to presumed $H$. pylori infection [15-18]. However, factors such as the prevalence of $H$. pylori in the home country and the timing of immigration play important roles [18]. Therefore, classifying all immigrants as high-risk may not be appropriate. Moreover, unanswered questions remain regarding the impact of immigration and foreign birth on future cancer risk $[19,20]$. Large-scale studies of individual immigrants have not been performed, because of limitations in data and follow up at this time. As yet, no study has attempted to identify the impact of region of birth (and the H. pylori prevalence in that region) on future gastric adenocarcinoma, accounting for anatomic subsite. Doing so in a US population is important in that the US is a particularly diverse country with a unique makeup of foreign-born individuals and a unique epidemiology of gastric adenocarcinoma subtypes. Here, we sought to determine whether the incidences of gastric cancer subtypes are associated with the percentage of certain foreignborn populations in different regions across the US.

\section{Materials and methods}

Using the Surveillance, Epidemiology, and End Results (SEER) Program, we identified gastric adenocarcinomas diagnosed between 2006-2017 as cardia, non-cardia, or unknown. After identifying primary gastric tumors, we included only adenocarcinomas (excluding leukemia, lymphoma, mesothelioma, and Kaposi sarcomas, etc.). We then identified gastric adenocarcinomas by location, using the SEER Program Coding and Staging Manual [21]. Codes for non-cardia cancers were: C16.1, C16.2, C16.3, C16.4, C16.5, and C16.6. The code C16.0 designated cardia cancers. The codes C16.8 and C16.9 designated overlapping and unspecified cancers.

For each cancer, SEER provides the postal code at diagnosis. This was used to determine the metropolitan statistical area (MSA) at diagnosis. For each MSA, using 2010 census data and data from the Migration Policy Institute, we identified total population, age composition of the population, and percent foreign-born [22,23]. Age-standardized rates were used [24]. Foreign-born regions were classified using the United Nations geo scheme of geographic areas. We used linear regression models to identify the coefficients of each foreign-born region. Despite the outcome being rates per 100,000, which usually exhibit non-normality, in this case we verified the normality of the error of the regression, suggesting linear regression was appropriate. Both residual and regression fits for these large population statistics suggested normal distribution, with linear regression providing a better fit than the Poisson and Negative Binomial assumptions. This allowed us to determine whether the incidence of gastric cancer in each MSA was associated with specific foreign-born populations. Variables indicating foreign-born individuals consisted of groups made available by the data source, and some groups with high similarities were grouped in order to reduce the degrees of freedom used in the analysis. This was important, given the limited number of MSAs available, in order to control for the age characteristics of each. The incidence of gastric cancer (classified as cardia, noncardia, and total) was estimated per MSA as the number of cases divided by the total population of the MSA. Age-standardized rates were used, using 5-year age groups starting at 15-19 and ending with $85+$, from the 2010 US Census [22,25,26]. The regression was repeated for cardia, non-cardia and total (including overlapping or unknown location) gastric cancers. Coefficients and P-values were produced for each regression component. A P-value of $<0.05$ was considered significant. All analyses were performed using $\mathrm{R}$ version 4.0.0.

In a sub-analysis, we focused on Asian-born persons. We used SEER data to further classify patient origin, and identified patients classified as being from China (including Taiwan), Japan and Korea, regions with notably high incidence [12]. In this manner, we looked for strong associations with any particular country. This model also included an "other Asian" category that excluded the above countries, to avoid creating collinearity. Because of limitations in statistical power, it was not feasible to define further subsets of foreign-born regions for patients outside these high-risk countries.

Given the in-silico modeling and publicly available data, institutional review board approval was not required.

\section{Results}

We identified 32 MSAs, with a total of 55,937 gastric adenocarcinoma diagnoses between 2006 and 2016. These MSAs and their foreign-born populations are depicted in Supplementary Table 1 . In total, the MSAs had a median of $16.0 \%$ foreign-born individuals (interquartile range [IQR] $7.53-22.0 \%)$. Of the total 55,937 adenocarcinomas, 26,213 (46.9\%) were non-cardia, 15,298 (27.4\%) were cardia, and $14,426(25.8 \%)$ were overlapping or not otherwise specified. Median age at diagnosis was similar across all groups at 69 years (IQR 58-79). Cardia adenocarcinoma patients were more likely to be male than non-cardia $(76.8 \%$ vs. $53.8 \%, \mathrm{P}<0.001)$ and more likely to be white $(86.0 \%$ vs. $61.1 \%, \mathrm{P}<0.001)$. 
Generalized linear model results were obtained for noncardia, cardia and total gastric cancers. Table 1 displays the age-standardized results of the model for non-cardia adenocarcinomas. Per 100,000 persons, there was no foreignborn population that was significantly associated with higher levels of non-cardia cancers in an MSA. A greater proportion of African-born individuals was associated with a non-significantly lower incidence of in non-cardia cancers (coefficient 2.19, $\mathrm{P}=0.11$ ). For cardia cancers, a greater percentage of Eastern European-born individuals in an MSA was associated with a higher incidence of cardia cancers (coefficient 1.32, $\mathrm{P}=0.02$ ) (Table 2). Supplementary Table 2 displays the coefficients of the model when considering all gastric cancers.

A subanalysis of those countries with high rates of cancer and H. pylori (China, Japan, Korea) was performed. Table 3 displays the age-standardized results of this model for noncardia adenocarcinomas. A greater percentage of Japaneseborn individuals in an MSA was associated with a higher incidence of non-cardia cancers (coefficient 2.48, $\mathrm{P}=0.03$ ). Korean or Chinese origin was not associated with a significantly higher risk, but a greater percent of persons born in other Asian countries was associated with a higher incidence of non-cardia cancers (coefficient 85.91, $\mathrm{P}=0.01$ ). Supplementary Tables 3 and 4 display the results for Asian-born populations with cardia cancers and all gastric adenocarcinomas.

The results of an age-standardized model of all foreignborn individuals are presented in Supplementary Table 5. They show that a greater percentage of foreign-born populations (all countries) in an MSA is associated with a slightly higher risk of non-cardia and all gastric cancers (non-cardia: coefficient $0.13, \mathrm{P}<0.001$ and all gastric adenocarcinomas: coefficient $0.22, \mathrm{P}<0.001)$. Supplementary Table 6 displays standardized incidence rates per 100,000 persons by MSA.

\section{Discussion}

Here, we present a generalized linear model depicting the association between the observed incidence of gastric adenocarcinoma and the percentage of foreign-born individuals from different global regions. It has generally been thought that people who immigrate from regions with a high incidence of gastric cancer to regions of low incidence maintain a higher risk of gastric cancer, though not as high as in their native country [15]. This apparent shift in risk of disease away from that prevailing in their country of origin and towards that of the host country could be an excellent epidemiologic marker for the contributions of environment and genetics. Most notably, we find that a greater percentage of Eastern European-born individuals in an MSA is associated with a higher incidence of cardia gastric adenocarcinomas. Among Asian-born individuals, a greater percentage of Japanese and non-Korean or Chinese-born individuals in an MSA is associated with a higher incidence of non-cardia gastric adenocarcinomas.

The finding that Eastern European-born individuals in the US are at greater risk for cardia cancers is consistent
Table 1 Results of an age-standardized generalized linear model of non-cardia adenocarcinomas

\begin{tabular}{lcc}
\hline Geographic area & Coefficient & P-value \\
\hline Per percent foreign born in: & & \\
\hline Africa & -2.19 & 0.11 \\
\hline Central America & 0.12 & 0.11 \\
\hline South America & 0.74 & 0.36 \\
\hline Caribbean & -1.09 & 0.15 \\
\hline North America & 198.37 & 0.15 \\
\hline Northern Europe & 3.08 & 0.57 \\
\hline Western Europe & -6.39 & 0.35 \\
\hline Eastern Europe & 1.50 & 0.07 \\
\hline Eastern Asia & 0.47 & 0.20 \\
\hline South Central Asia & -0.55 & 0.17 \\
\hline South Eastern Asia & 0.31 & 0.24 \\
\hline Western Asia & 0.39 & 0.63 \\
\hline Coefficients are per 100,000 & & \\
\hline
\end{tabular}

Table 2 Results of an age-standardized generalized linear model of cardia adenocarcinomas

\begin{tabular}{lcc}
\hline Geographic area & Coefficient & P-value \\
\hline Per percent foreign born in: & & \\
\hline Africa & -0.48 & 0.59 \\
\hline Central America & 0.06 & 0.24 \\
\hline South America & 0.10 & 0.85 \\
\hline Caribbean & -0.69 & 0.17 \\
\hline North America & -29.44 & 0.74 \\
\hline Northern Europe & 1.75 & 0.63 \\
\hline Western Europe & -1.58 & 0.73 \\
\hline Eastern Europe & 1.32 & 0.02 \\
\hline Eastern Asia & -0.15 & 0.55 \\
\hline South Central Asia & -0.11 & 0.67 \\
\hline South Eastern Asia & 0.11 & 0.54 \\
\hline Western Asia & -0.10 & 0.85 \\
\hline Coefficients are per 100,000 & & \\
\hline
\end{tabular}

Coefficients are per 100,000

Table 3 Results of an age-standardized generalized linear model of non-cardia adenocarcinomas, evaluating Asian born populations

\begin{tabular}{lcc}
\hline Geographic area & Coefficient & P-value \\
\hline Per percent individuals of: & & \\
Asia (excluding China, Japan, Korea) & 85.91 & 0.01 \\
China & -0.45 & 0.22 \\
Japan & 2.48 & 0.03 \\
Korea & 1.48 & 0.19 \\
\hline
\end{tabular}

Coefficients are per 100,000 
with known epidemiologic trends [27]. Eastern Europe is considered to be a high-risk area for all stomach cancers, and has notably seen a rise in cardia gastric cancers within the last half century [28-30]. And while Eastern Europe is considered to have a high burden of stomach cancers, with an agestandardized incidence of 17.7 per 100,000 population, East Asia is even higher, at 28.6 per 100,000 population [31]. These are both markedly higher than North America, which has an age-standardized incidence of 6.5 per 100,000 population. Our findings regarding Asian immigrants underline their high-risk nature, but also the complexities in immigration and future cancer risk: notably, that a greater percentage of Korean- or Chinese-born individuals is not associated with higher rates of cancer in a MSA, whereas greater percentages of other Asianborn (including Japanese) individuals are so associated [32,33]. We found a non-statistically significant association between African-born individuals and MSA incidence, consistent with the theory of the "African enigma", whereby high rates of $H$. pylori do not translate into high rates of gastric cancer. This is probably attributable to other host, bacterial or environmental causes, though future studies should investigate this potential discordance. Our findings add to the growing literature that will guide screening recommendations. Screening for gastric cancer, a relatively low prevalence malignancy, in the US, is being developed by national societies at this time. However, given the need to balance cost and unnecessary testing, it will be most effective if tailored to high-risk persons [2]. Accordingly, studies elucidating the importance of foreignborn status on gastric cancer are essential in order to tailor screening strategies.

The persistently elevated increase of gastric cancer risk among immigrants has largely been attributed to $H$. pylori prevalence, but even US-born descendants of immigrants have been reported to have a higher cancer risk [19]. A meta-analysis found that immigrants who moved from certain countries or regions with a high incidence of gastric cancer to countries with a lower incidence still had higher cancer incidence and mortality than non-immigrants [15]. The investigators found pooled standardized incidence rates of 1.66 (95\% confidence interval [CI] 1.52-1.80) for men and 1.83 (95\%CI 1.69-1.98) for women. Limitations to this meta-analysis include the fact that all foreign-born populations were analyzed en bloc and that there was a lack of granularity regarding the anatomic subsite; neither limitation applies to our study.

A large number of immigrant gastric cancer risk studies in the US have focused on East Asian populations, given the high prevalence of gastric cancer in East Asian countries [17,19,34,35]. In our study, we found that a greater percentage of Korean- and Chinese-born individuals was not associated with higher rates of cancer in an MSA, whereas higher percentages of other Asianborn (including Japanese) individuals had such an association. We hypothesize that this is due to the dynamic nature of immigration, assimilation and changing cancer epidemiology, not captured by population level statistics. For example, while one study reported that US persons of Japanese descent carry a higher future risk of increased gastric cancer, another found that Korean-Americans adopt the risk of the country where they live and have a higher risk of cardia cancers, comparable to native US persons-an interesting finding, as cardia cancers are more associated with "western lifestyles" [19,36]. Obesity and metabolic syndrome components are considered to be strongly associated with gastric cardia cancers, perhaps even interacting with $H$. pylori $[37,38]$. These shifting risks between cardia and non-cardia cancer of immigrants from countries otherwise similar in their $H$. pylori prevalence, gastric cancer epidemiology and public health initiatives against gastric cancer, suggest nuances that may not be evident in populationlevel data. These include diet, in both the home country and the US, likely to be influenced by geography, acculturation, and residing in cultural enclaves, as well as other host, bacterial and environmental factors.

Furthermore, H. pylori itself is a complex risk factor. $H$. pylori is considered to infect half of the world's population, though levels of infection may be decreasing. Africa, Western Asia and South America are considered to have the highest burden of infection, but the prevalence of $H$. pylori varies among and within geographic regions and is strongly linked to socioeconomic status, even within developed countries $[9,39]$. There are known variations in pathogenicity, potentially explaining differences in carcinogenesis, even among persons of the same country [40,41].

There are several limitations to this study. Most notably, it was a population-level study, without access to individual data, and was therefore unable to adjust for potential individual confounders, including $H$. pylori, the most well-known risk factor for gastric cancer. In this study, we used population averages to model the association between observed cancer incidence and variables of interest. Limitations in statistical power restricted the ability to detect an association (particularly between African-born individuals and gastric cancer), the ability to test for interactions between age and foreign-born group (which could parallel immigration patterns), and the post hoc inclusion of sex. Among geo scheme regions there was a lack of granularity. For example, while Africa was considered one region (because of available census and $H$. pylori prevalence data), there is known variation in $H$. pylori prevalence among African regions [7,42]. Similarly, we were unable to granularly analyze other Asian-born populations. SEER did not provide granular data with which we could break up African-born into multiple groups; as we note, this is important, considering the African diversity of $H$. pylori. It is possible there was misclassification among SEER data, both for cancers and for variables such as postal code. In particular, there could have been misclassification of the cancer subtype, i.e., cardia and non-cardia, or histology (adenocarcinoma subtypes). This is a well-known issue in the gastric cancer literature, stemming in part from the changing nomenclature, relatively recent implementation of a separate administrative code, and a lack of stable consensus definitions around cardia cancers [43]. Therefore, this is a limitation of most large database studies relating to gastric cancer. SEER is a widely used database, and these misclassifications should not be more pronounced than in any other large database. It is also possible that a patient moves around the time of cancer diagnosis, thus misclassifying their assigned MSA. Lastly, even among MSAs, there were 
foreign-born individuals without a classified region of birth. However, our total foreign-born population estimates were in line with Census statistics [44].

Our strengths are related to the methodology and the ability to utilize population level statistics to overlay immigration and cancer. We were able to analyze foreign-born populations as a percentage of a discrete geographical area (the MSA) and further analyze cancers by subsite, which is important given the demographic differences between cardia and non-cardia cancers [4-6]. Using MSA provides even more granularity, given that geographic variability in gastric cancer has been previously noted [45]. We demonstrated here that a greater percentage of Eastern European born individuals in an MSA was associated with a higher incidence of cardia gastric adenocarcinomas. Among Asian-born individuals, Korean or Chinese origin was not associated with a significantly higher risk, but a greater percentage of persons born in other Asian countries, including Japan, was associated with a higher incidence of non-cardia gastric adenocarcinomas in an MSA. A greater percentage of African-born persons in a population was not associated with gastric cancer. This was perhaps due to limitations in statistical power, or differences in host or bacterial factors. Overall, our study adds to the growing literature on the importance of immigration in cancer risk. Immigration's impact upon future cancer risk is an important and growing area of research interest, and consensus guidelines suggest tailoring gastric cancer screening to high-risk immigrant groups [32]. This study will help guide the screening of those populations most likely to benefit.

\section{Summary Box}

\section{What is already known:}

- Immigrants are thought to be at a higher risk of gastric cancer, particularly non-cardia gastric cancer, even once they move to the United States; however, this risk has not been demonstrated at a population level

\section{What the new findings are:}

- We determined whether the incidence of gastric cancer in a geographic area was related to the percentage of foreign-born individuals from different global regions

- We found that a greater percentage of Eastern European-born individuals was associated with a higher incidence of cardia gastric adenocarcinomas

- Among Asian-born individuals, a greater percentage of persons born in other Asian countries, including Japan, was associated with a higher incidence of non-cardia gastric adenocarcinomas

\section{References}

1. Karimi P, Islami F, Anandasabapathy S, Freedman ND, Kamangar F. Gastric cancer: descriptive epidemiology, risk factors, screening, and prevention. Cancer Epidemiol Biomarkers Prev 2014;23:700-713.

2. Kim GH, Liang PS, Bang SJ, Hwang JH. Screening and surveillance for gastric cancer in the United States: Is it needed? Gastrointest Endosc 2016;84:18-28.

3. Siegel R, Naishadham D, Jemal A. Cancer statistics for Hispanics/ Latinos, 2012. CA Cancer J Clin 2012;62:283-298.

4. Helicobacter and Cancer Collaborative Group. Gastric cancer and Helicobacter pylori: a combined analysis of 12 case control studies nested within prospective cohorts. Gut 2001;49:347-353.

5. Kim JH, Cheung DY. Must-have knowledge about the Helicobacter pylori-negative gastric cancer. Gut Liver 2016;10:157-159.

6. Kumar S, Long JM, Ginsberg GG, Katona BW. The role of endoscopy in the management of hereditary diffuse gastric cancer syndrome. World J Gastroenterol 2019;25:2878-2886.

7. Correa P, Piazuelo MB. Helicobacter pylori infection and gastric adenocarcinoma. US Gastroenterol Hepatol Rev 2011;7:59-64.

8. Kumar S, Metz DC, Ellenberg S, Kaplan DE, Goldberg DS. Risk factors and incidence of gastric cancer after detection of Helicobacter pylori infection: a large cohort study. Gastroenterology 2019;158:527-536.e7.

9. Crowe SE. Helicobacter pylori infection. $N$ Engl J Med 2019;380:1158-1165.

10. Ferlay J, Soerjomataram I, Dikshit R, et al. Cancer incidence and mortality worldwide: sources, methods and major patterns in GLOBOCAN 2012. Int J Cancer 2015;136:E359-E386.

11. Tsuda M, Asaka M, Kato M, et al. Effect on Helicobacter pylori eradication therapy against gastric cancer in Japan. Helicobacter 2017;22:e12415.

12. Kim Y, Park J, Nam BH, Ki M. Stomach cancer incidence rates among Americans, Asian Americans and Native Asians from 1988 to 2011. Epidemiol Health 2015;37:e2015006.

13. Hussein NR. Helicobacter pylori and gastric cancer in the Middle East: a new enigma? World J Gastroenterol 2010;16:3226-3234.

14. Mbulaiteye SM, Hisada M, El-Omar EM. Helicobacter pylori associated global gastric cancer burden. Front Biosci (Landmark Ed) 2009;14:1490-1504.

15. Pabla BS, Shah SC, Corral JE, Morgan DR. Increased incidence and mortality of gastric cancer in immigrant populations from high to low regions of incidence: a systematic review and meta-analysis. Clin Gastroenterol Hepatol 2020;18:347-359.

16. Hallowell BD, Endeshaw M, Senkomago V, Razzaghi H, McKenna MT, Saraiya M. Gastric cancer mortality rates among US and foreign-born persons: United States 2005-2014. Gastric Cancer 2019;22:1081-1085.

17. Liu Z, Lin C, Mu L, et al. The disparities in gastrointestinal cancer incidence among Chinese populations in Shanghai compared to Chinese immigrants and indigenous non-Hispanic white populations in Los Angeles, USA. Int J Cancer 2020;146:329-340.

18. Ziadeh C, Ziogas A, Anton-Culver H. Cancer risk in different generations of Middle Eastern immigrants to California, 19882013. Int J Cancer 2017;141:2260-2269.

19. Kamineni A, Williams MA, Schwartz SM, Cook LS, Weiss NS. The incidence of gastric carcinoma in Asian migrants to the United States and their descendants. Cancer Causes Control 1999;10:77-83.

20. Lee J, Demissie K, Lu SE, Rhoads GG. Cancer incidence among Korean-American immigrants in the United States and native Koreans in South Korea. Cancer Control 2007;14:78-85.

21. SEER Program Coding and Staging Manual. Available from: https://seer.cancer.gov/manuals/2018/AppendixC/Surgery_ Codes_Stomach_2018.pdf [Accessed 4 May 2021].

22. US Census Bureau. American Community Survey (ACS). Available 
from: https://www.census.gov/programs-surveys/acs [Accessed 4 May 2021].

23. Migration Policy Institute. U.S. Immigrant Population by Metropolitan Area. Available from: https://www.migrationpolicy. org/programs/data-hub/charts/us-immigrant-populationmetropolitan-area [Accessed 4 May 2021].

24. Anderson WF, Rabkin CS, Turner N, Fraumeni JF Jr, Rosenberg PS, Camargo MC. The changing face of noncardia gastric cancer incidence among US non-Hispanic whites. J Natl Cancer Inst 2018;110:608-615.

25. White MC, Holman DM, Boehm JE, Peipins LA, Grossman M, Henley SJ. Age and cancer risk: a potentially modifiable relationship. Am J Prev Med 2014;46:S7-S15.

26. United States and Puerto Rico Cancer Statistics, 1999-2015 Incidence Archive Request. Available from: https://wonder.cdc. gov/cancer-v2015.html [Accessed 4 May 2021].

27. Balakrishnan M, George R, Sharma A, Graham DY. Changing trends in stomach cancer throughout the world. Curr Gastroenterol Rep 2017;19:36.

28. Mousavi SM, Hemminki K. Cancer incidence, trends, and survival among immigrants to Sweden: a population-based study. Eur J Cancer Prev 2015;24 Suppl 1:S1-S63.

29. Botterweck AA, Schouten LJ, Volovics A, Dorant E, van Den Brandt PA. Trends in incidence of adenocarcinoma of the oesophagus and gastric cardia in ten European countries. Int $J$ Epidemiol 2000;29:645-654.

30. European Network of Cancer Registries. Stomach cancer (SC) Factsheet. Available from: https:/www.encr.eu/sites/default/files/factsheets/ ENCR_Factsheet_Stomach_2017.pdf [Accessed 4 May 2021].

31. Correction to Lancet Gastroenterol Hepatol 2020; 5: 42-54. Lancet Gastroenterol Hepatol 2020;5:e2.

32. El-Serag HB, Kao JY, Kanwal F, et al. Houston consensus conference on testing for Helicobacter pylori infection in the United States. Clin Gastroenterol Hepatol 2018;16:992-1002.

33. Gupta S, Tao L, Murphy JD, et al. Race/ethnicity-, socioeconomic status-, and anatomic subsite-specific risks for gastric cancer. Gastroenterology 2019;156:59-62.

34. Kolonel LN, Nomura AM, Hirohata T, Hankin JH, Hinds MW.
Association of diet and place of birth with stomach cancer incidence in Hawaii Japanese and Caucasians. Am J Clin Nutr 1981;34:2478-2485.

35. Maskarinec G, Noh JJ. The effect of migration on cancer incidence among Japanese in Hawaii. Ethn Dis 2004;14:431-439.

36. Mueller JL, Kim DH, Stapleton S, et al. Nature versus nurture: the impact of nativity and site of treatment on survival for gastric cancer. Gastric Cancer 2019;22:446-455.

37. Lauby-Secretan B, Scoccianti C, Loomis D, Grosse Y, Bianchini F, Straif K; International Agency for Research on Cancer Handbook Working Group. Body fatness and cancer-viewpoint of the IARC Working Group. N Engl J Med 2016;375:794-798.

38. Kountouras J, Polyzos SA, Doulberis M, et al. Potential impact of Helicobacter pylori-related metabolic syndrome on upper and lower gastrointestinal tract oncogenesis. Metabolism 2018;87:18-24.

39. Hooi JKY, Lai WY, Ng WK, et al. Global prevalence of Helicobacter pylori infection: systematic review and meta-analysis. Gastroenterology 2017;153:420-429.

40. Bakhti SZ, Latifi-Navid S, Zahri S, Bakhti FS, Hajavi N, Yazdanbod A. Are Helicobacter pylori highly cytotoxic genotypes and cardia gastric adenocarcinoma linked? Lessons from Iran. Cancer Biomark 2017;21:235-246.

41. Bakhti SZ, Latifi-Navid S, Zahri S, Yazdanbod A. Inverse association of Helicobacter pylori cagPAI genotypes with risk of cardia and noncardia gastric adenocarcinoma. Cancer Med 2019;8:4928-4937.

42. Holcombe C. Helicobacter pylori: the African enigma. Gut 1992;33:429-431.

43. Ekström AM, Signorello LB, Hansson LE, Bergström R, Lindgren A, Nyrén O. Evaluating gastric cancer misclassification: a potential explanation for the rise in cardia cancer incidence. J Natl Cancer Inst 1999;91:786-790.

44. The foreign-born population in the United States. Available from: https://www.census.gov/newsroom/pdf/cspan_fb_slides.pdf [Accessed 4 May 2021].

45. Wang Z, Graham DY, Khan A, et al. Incidence of gastric cancer in the USA during 1999 to 2013: a 50-state analysis. Int J Epidemiol 2018;47:966-975. 


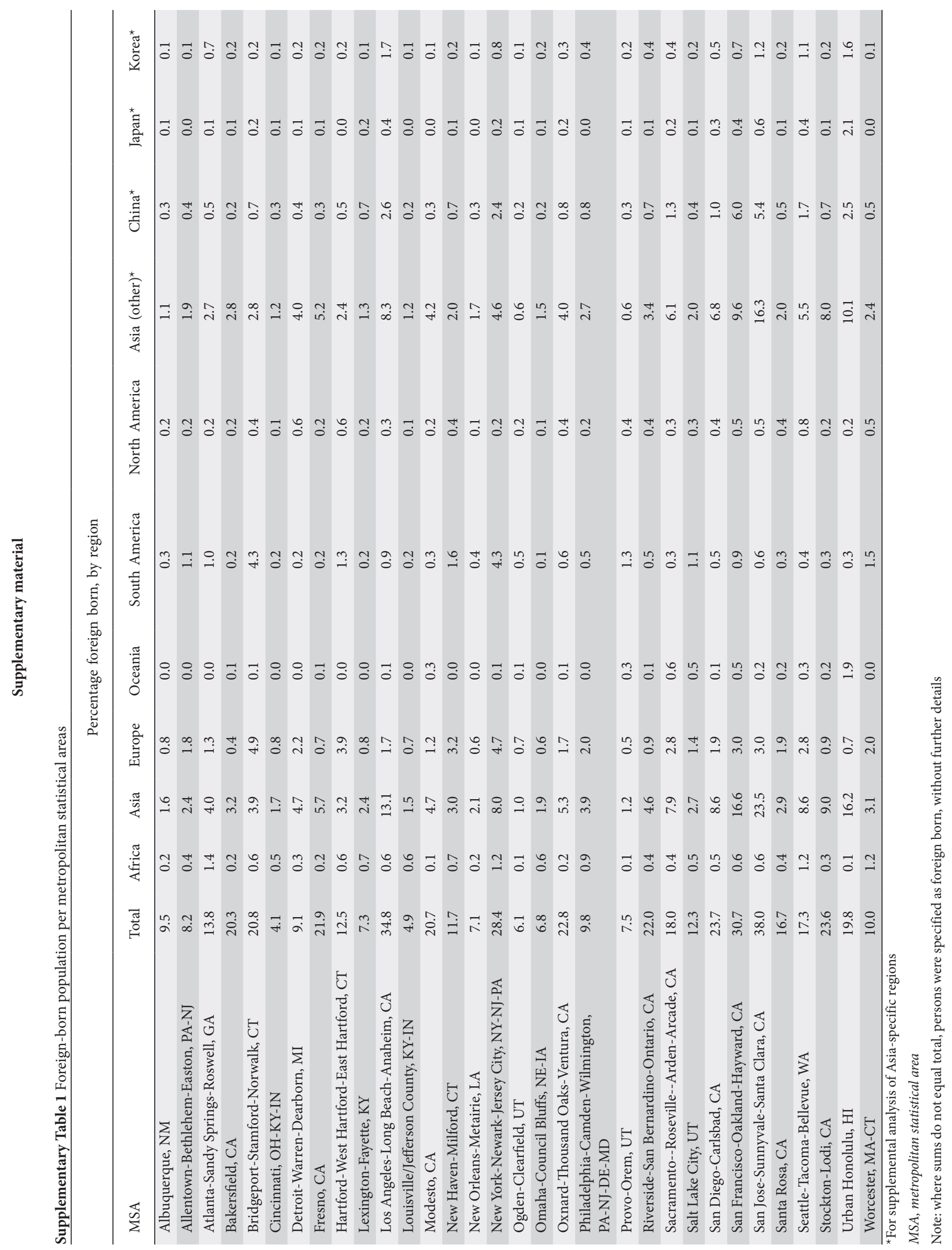


Supplementary Table 2 Results of an age-standardized generalized linear model of all gastric adenocarcinomas

\begin{tabular}{lcc}
\hline Geographic area & Coefficient & P-value \\
\hline Per percent foreign born in: & & \\
\hline Africa & -3.19 & 0.28 \\
\hline Central America & 0.25 & 0.12 \\
\hline South America & 1.53 & 0.39 \\
\hline North America & 233.30 & 0.43 \\
\hline Caribbean & -2.48 & 0.14 \\
\hline Northern Europe & 3.07 & 0.80 \\
\hline Western Europe & -7.67 & 0.61 \\
\hline Eastern Europe & 3.50 & 0.06 \\
\hline Eastern Asia & 0.36 & 0.65 \\
\hline South Central Asia & -0.96 & 0.27 \\
\hline South Eastern Asia & 0.64 & 0.27 \\
\hline Western Asia & 0.32 & 0.86 \\
\hline
\end{tabular}

Coefficients are per 100,000

Supplementary Table 3 Results of an age-standardized generalized linear model of cardia adenocarcinomas, evaluating Asian-born populations

\begin{tabular}{lcc}
\hline Geographic area & Coefficient & P-value \\
\hline Per percent individuals of: & & \\
Asia (excluding China, Japan, Korea) & 43.09 & 0.06 \\
China & -0.27 & 0.30 \\
Japan & 0.35 & 0.65 \\
Korea & 0.32 & 0.68 \\
\hline
\end{tabular}

Supplementary Table 4 Results of an age-standardized generalized linear model of all gastric adenocarcinomas, evaluating Asian born populations

\begin{tabular}{lcc}
\hline Geographic area & Coefficient & P-value \\
\hline Per percent individuals of: & & \\
Asia (excluding China, Japan, Korea) & 167.64 & 0.02 \\
China & -1.04 & 0.19 \\
Japan & 3.92 & 0.11 \\
\hline Korea & 2.51 & 0.30 \\
\hline
\end{tabular}

Coefficients are per 100,000

Supplementary Table 5 Results of an age-standardized generalized linear model of all foreign-born individuals

\begin{tabular}{lcc}
\hline Cancer classification & Coefficient & P-value \\
\hline Non-cardia & 0.13 & $<0.001$ \\
Cardia & 0.04 & 0.11 \\
All & 0.22 & $<0.001$ \\
\hline Coefficients are per 100,000 cases & &
\end{tabular}

Coefficients are per 100,000 
Supplementary Table 6 Age standardized incidence rates per 100,000 persons by metropolitan statistical area (MSA)

\begin{tabular}{|c|c|c|c|}
\hline MSA & Non-cardia & Cardia & Not otherwise specified \\
\hline Albuquerque, NM & 4.14 & 2.28 & 3.35 \\
\hline Allentown-Bethlehem-Easton, PA-NJ & 0.51 & 0.42 & 0.38 \\
\hline Atlanta-Sandy Springs-Roswell, GA & 4.81 & 2.65 & 2.87 \\
\hline Bakersfield, CA & 4.31 & 2.44 & 3.24 \\
\hline Bridgeport-Stamford-Norwalk, CT & 6.31 & 3.57 & 3.25 \\
\hline Cincinnati, OH-KY-IN & 0.54 & 0.72 & 0.44 \\
\hline Detroit-Warren-Dearborn, MI & 4.68 & 3.44 & 2.5 \\
\hline Fresno, CA & 5.1 & 3.04 & 3 \\
\hline Hartford-West Hartford-East Hartford, CT & 5.33 & 4.29 & 2.55 \\
\hline Lexington-Fayette, KY & 3.69 & 2.96 & 1.99 \\
\hline Los Angeles-Long Beach-Anaheim, CA & 7.54 & 2.8 & 3.46 \\
\hline Louisville/Jefferson County, KY-IN & 3.07 & 2.89 & 1.75 \\
\hline Modesto, CA & 3.98 & 3.6 & 2.31 \\
\hline New Haven-Milford, CT & 4.6 & 4.6 & 3.12 \\
\hline New Orleans-Metairie, LA & 5.66 & 3.2 & 3.08 \\
\hline New York-Newark-Jersey City, NY-NJ-PA & 1.85 & 1.16 & 1.25 \\
\hline Ogden-Clearfield, UT & 2.52 & 2.11 & 1.96 \\
\hline Omaha-Council Bluffs, NE-IA & 0.47 & 0.72 & 0.28 \\
\hline Oxnard-Thousand Oaks-Ventura, CA & 4.73 & 3.02 & 2.03 \\
\hline Philadelphia-Camden-Wilmington, PA-NJ-DE-MD & 1.03 & 0.83 & 0.69 \\
\hline Provo-Orem, UT & 2.27 & 1.82 & 1.45 \\
\hline Riverside-San Bernardino-Ontario, CA & 4.65 & 2.77 & 2.76 \\
\hline Sacramento--Roseville--Arden-Arcade, CA & 4.36 & 3.29 & 2.22 \\
\hline Salt Lake City, UT & 2.88 & 2.41 & 2.28 \\
\hline San Diego-Carlsbad, CA & 4.15 & 2.88 & 2.43 \\
\hline San Francisco-Oakland-Hayward, CA & 6.02 & 2.92 & 2.69 \\
\hline San Jose-Sunnyvale-Santa Clara, CA & 6.27 & 3.04 & 2.71 \\
\hline Santa Rosa, CA & 3.89 & 3.59 & 1.91 \\
\hline Seattle-Tacoma-Bellevue, WA & 3.63 & 3.81 & 2.52 \\
\hline Stockton-Lodi, CA & 4.63 & 3.4 & 3.63 \\
\hline Urban Honolulu, HI & 8.33 & 2.38 & 4.08 \\
\hline Worcester, MA-CT & 0.37 & 0.75 & 0.24 \\
\hline
\end{tabular}

